\title{
Sociodemographic factors and the outcome of rheumatoid arthritis in young women
}

Theodora P M Vliet Vlieland, Neeltje A Buitenhuis, Derkjen van Zeben, Jan P Vandenbroucke, Ferdinand C Breedveld, Johanna M W Hazes

\begin{abstract}
Objective-To investigate the impact of sociodemographic factors on the outcome of rheumatoid arthritis (RA).

Methods-A group of 138 women with RA of recent onset and a mean duration of follow up of 5.8 years was studied. Additional information on sociodemographic variables at disease onset (level of formal education, marital status and employment status) was related to the initial disease severity and various outcome measures.

Results-Patients with lower levels of education showed a trend towards a worse outcome, according to Health Assessment Questionnaire (HAQ) score, erosion score and the patient's and physician's assessment of outcome at the last visit. However, we also found a trend towards an association between lower levels of education and more severe disease at onset, as measured by HAQ score, erosion score and the number of painful and swollen joints. The association between lower levels of education and poorer outcome of RA was weakened after correction for the initial disease severity. Results of other sociodemographic variables were equivocal.

Conclusions-Differences in severity of RA between patients with different levels of education develop or are present in the early stages of the disease.
\end{abstract}

(Ann Rheum Dis 1994; 53: 803-806)

The course and outcome of rheumatoid arthritis (RA) vary greatly among patients. In addition to disease characteristics, sociodemographic variables are receiving increasing attention as determinants of severity of RA.

In a number of studies, lower formal education level was found to be associated with increased mortality and morbidity. ${ }^{1-3}$ The differences in outcome according to formal education level could not be explained by age or duration of disease. ${ }^{13}$ In other studies, however, a consistent association between education level and disease outcome was not found, ${ }^{4-6}$ or did not appear important after additional adjustment for age, disease duration or work hours. ${ }^{7-9}$ The factors age and disease duration may give rise to spurious associations, as patients with lower levels of education are likely to be older, and might seek initial medical care at a later, more advanced stage of the disease. Therefore, the question remains, whether patients with lower levels of education have a poorer disease outcome or more advanced disease at study entry.

Marital status is another sociodemographic variable that is associated with the outcome of RA in some studies. Never having been married, or being divorced, separated or widowed appeared to be a positive predictor of functional disability. ${ }^{2} 7910$ Other studies found an inconsistent or no association between marital status and outcome of RA. ${ }^{458}$

Another sociodemographic variable predicting future disability is work status. ${ }^{59}$ The number of work hours and occupation have been found to be related to the course of functional disability over eight years of follow up. ${ }^{9}$ However, the average disease duration in patients in that prospective study was more than 10 years at study entry, and it is known from other studies that, within approximately 10 years of disease duration, $50 \%$ of patients with RA who had been working during the year of diagnosis become no longer employed, mostly because of the RA. ${ }^{11-13}$ Sociodemographic factors that are likely to be influenced by the disease itself are therefore suitable for predicting outcome of RA only if measured at disease onset.

The present study was undertaken retrospectively in a cohort of women with RA of recent onset and mean follow up duration of six years. Its aim was to investigate, conditional on the initial presentation, if sociodemographic variables measured at disease onset are predictive markers for the outcome of RA, measured in various ways including functional disability, erosion score, and physician's and patient's global assessment.

\section{Patients and methods}

PATIENTS

The cohort of women with RA that participated in the present study was described previously. ${ }^{14}$ Briefly, they were 138 women aged $20-50$ years who consecutively attended the outpatient clinic of the Department of Rheumatology of the Leiden University Hospital for the first time between 1982 and 1986 , and who had symptoms of recent onset (less than five years). All patients fulfilled the 
American Rheumatism Association (ARA) criteria for definite $\mathrm{RA}^{15}$ and $93 \%$ fulfilled the 1987 revised ARA criteria ${ }^{16}$ at some time later in the study. Patients first participated in a case-control study and subsequently enrolled into a follow up study. The last visit in connection with the follow up study was approximately by the end of 1991 .

Among others, measures of outcome that were determined at the last visit to the outpatient clinic were the Health Assessment Questionnaire (HAQ) score, ${ }^{17}$ erosion score ${ }^{18}$ and the physician's opinion of mild or progressive disease. ${ }^{19}$

\section{METHODS}

In January 1993 a questionnaire was sent by mail to 136 of the 138 patients (the addresses of two patients were unknown). The questionnaire comprised questions about the highest level of formal education level that was achieved (eight categories varying from lowest: primary school to highest: university) and working status of the patient in the year before the onset of RA. Answers to the questions on employment status were compared with the sociodemographic data that were entered in the medical record at the first visit. Marital status at disease onset had already been recorded. In addition, patient's global assessment of disease outcome was measured by a verbal rating scale (mild or progressive). If subjects did not respond to the questionnaire within three weeks, a reminder was sent.

\section{DATA ANALYSIS}

Eight categories of formal education were condensed into three levels (low, medium and high), marital status was divided into married and unmarried (including never married, widowed, divorced or separated) and employment status was divided into paid employment (including part-time employment) and no paid employment. Sociodemographic characteristics of the patients were compared with data from Dutch women of the same age range and, if available, from the same district in 1982 or 1983 , the period when the first women of the cohort RA patients visited the outpatient clinic. ${ }^{20}$

For each sociodemographic category the mean age at onset of symptoms, duration of symptoms at diagnosis and variables of disease severity at the first visit were calculated together with the $95 \%$ confidence interval (95\% CI). In the same way, the global outcome assessment by patient and physician and variables of disease severity at the last visit (with 95\% CI) were calculated. Differences between groups were tested by Mann-Whitney $U$, Kruskal-Wallis or the Pearson $\chi^{2}$ tests where appropriate. The risk of having a progressive disease course according to the patient or the physician, a high HAQ score $(\geq 1 \cdot 25)$ or high erosion score $(\geq 30)$ at the last visit for the different levels of education and the other sociodemographic variables was calculated using the logistic regression model. To adjust
Table 1 Disease characteristics of 127 women with rheumatoid arthritis

\begin{tabular}{lc}
\hline Mean (SD) & \\
Age at symptom onset (yr) & $35 \cdot 9(8 \cdot 7)$ \\
Duration of symptoms at diagnosis (yr) & $1 \cdot 5(1 \cdot 6)$ \\
Duration of follow up (yr) & $5 \cdot 8(1 \cdot 8)$ \\
HAQ score at last visit & $0 \cdot 790(0 \cdot 727)$ \\
No. $(\%)$ with & \\
Continuing positive rheumatoid factor & $91(71 \cdot 7)$ \\
Erosions at last visit & $100(78 \cdot 7)$ \\
Progressive disease according to physician & $67(52 \cdot 8)$ \\
Progressive disease according to patient & $30(23 \cdot 6)$ \\
\hline
\end{tabular}

for potential confounders age, duration of symptoms, use of oral contraceptives, and variables representing disease severity at initial presentation (erosion score, HAQ score, number of swollen joints, Ritchie score at first visit) were entered into the model. All statistical analyses were performed using the SPSS/PC statistical program, with a $p<0.05$ as level of statistical significance.

\section{Results}

Of the 136 women who were sent the questionnaire, 135 (99\%) responded, 129 $(95 \%)$ completing the questionnaire and six stating they were not willing to complete the survey. The follow up data of two of the 129 participants were insufficiently complete, so the data of 127 of the initial cohort of 138 patients $(92 \%)$ were available for analysis.

Table 1 shows disease characteristics of the patients. In the survey, patients were asked to judge their own disease outcome as mild or progressive, being unaware of the physician's opinion of disease outcome. In only $61 \%$ of the cases there was consensus of outcome assessment between patient and physician. Patients judged outcome of disease as mild more often than the physician.

Table 2 compares sociodemographic characteristics of the RA patients and Dutch women of the same age range. Compared with the reference population, there were fewer women with a medium education level and more with a low or high education level in the RA population. More women in the patient group were married and had paid employment at the onset of the disease compared with the reference population.

In table 3 the mean age, duration of symptoms and characteristics of disease severity are shown according to education

Table 2 Sociodemographic characteristics of 127 female patients with rheumatoid arthritis compared with data from Dutch women of the same age range (20-50) and the same district in 1982 or 1983

\begin{tabular}{|c|c|c|c|}
\hline & \multicolumn{2}{|c|}{ Patients } & \multirow{2}{*}{$\begin{array}{l}\text { Population } \\
(\%)\end{array}$} \\
\hline & No. & $\%$ & \\
\hline $\begin{array}{l}\text { Education level } \\
\text { Low } \\
\text { Medium } \\
\text { High } \\
\text { Unknown }\end{array}$ & $\begin{array}{r}78 \\
30 \\
18 \\
1\end{array}$ & $\begin{array}{r}61 \cdot 4 \\
23 \cdot 6 \\
14 \cdot 2 \\
0 \cdot 8\end{array}$ & $\begin{array}{r}53 \cdot 7 \\
29 \cdot 9 \\
10 \cdot 5 \\
5 \cdot 9\end{array}$ \\
\hline $\begin{array}{l}\text { Marital status } \\
\text { Married } \\
\text { Never married } \\
\text { Divorced, widowed, separated }\end{array}$ & $\begin{array}{r}102 \\
19 \\
6\end{array}$ & $\begin{array}{r}80 \cdot 3 \\
15 \cdot 0 \\
4 \cdot 7\end{array}$ & $\begin{array}{r}72 \cdot 4 \dagger \\
21.2 \dagger \\
6.4 \dagger\end{array}$ \\
\hline $\begin{array}{l}\text { Paid employment } \\
\text { Yes } \\
\text { No } \\
\text { Unknown }\end{array}$ & $\begin{array}{l}64 \\
40 \\
23 \\
\end{array}$ & $\begin{array}{l}50 \cdot 4 \\
31 \cdot 5 \\
18 \cdot 1 \\
\end{array}$ & $43 \cdot 8$ \\
\hline
\end{tabular}


Table 3 Age, duration of symptoms, and variables of disease severity at first visit to the outpatient clinic according to level of education, marital status and employment status in 127 female patients with rheumatoid arthritis

\begin{tabular}{|c|c|c|c|c|c|c|}
\hline & $\begin{array}{l}\text { Age } \\
(y r)\end{array}$ & $\begin{array}{l}\text { Duration of symptoms } \\
(y r)\end{array}$ & $\begin{array}{l}\text { Erosion score } \\
(y r)\end{array}$ & $H A Q$ score & $\begin{array}{l}\text { Number of } \\
\text { swollen joints }\end{array}$ & Ritchie score \\
\hline \multicolumn{7}{|l|}{ Education level } \\
\hline Low & $38 \cdot 3(36 \cdot 4$ to $40 \cdot 1)$ & $1.6(1.2$ to 1.9$)$ & $5 \cdot 1(2 \cdot 8$ to $7 \cdot 4)$ & $0.740(0.587$ to 0.894$)$ & $4.3(3.5$ to 5.0$)$ & $9 \cdot 4(7 \cdot 4$ to $11 \cdot 5)$ \\
\hline Medium & $32 \cdot 2^{\star}(29 \cdot 1$ to $35 \cdot 3)$ & $1.5(0.9$ to 2.1$)$ & $7 \cdot 8(2 \cdot 0$ to $13 \cdot 5)$ & $0.916+(0.657$ to 1.174$)$ & $4.9(3.6$ to 6.2$)$ & $10.3(6.7$ to 13.8$)$ \\
\hline High & $32 \cdot 9^{\star}(29 \cdot 2$ to $36 \cdot 6)$ & $1.5(0.6$ to 2.4$)$ & $1 \cdot 6(0 \cdot 4$ to $2 \cdot 7)$ & $0.448(0 \cdot 189$ to $0 \cdot 706)$ & $3 \cdot 3(2 \cdot 0$ to $4 \cdot 5)$ & $6 \cdot 3(4 \cdot 2$ to $8 \cdot 5)$ \\
\hline \multicolumn{7}{|l|}{ Marital status } \\
\hline Unmarried & $32 \cdot 5 \S(35 \cdot 1$ to $38 \cdot 4)$ & $1.4(0.7$ to 22$)$ & $1 \cdot 2 \oint(0 \cdot 4$ to $2 \cdot 1)$ & $0.793(0.508$ to 1.077$)$ & $3 \cdot 8(2 \cdot 8$ to $4 \cdot 8)$ & $8.5(5.5$ to 11.5$)$ \\
\hline Married & $36 \cdot 7(28 \cdot 7$ to $36 \cdot 4)$ & $1.6(1.3$ to 1.9$)$ & $6 \cdot 3(3.9$ to $8 \cdot 7)$ & $0.739(0.607$ to 0.872$)$ & $4.5(3 \cdot 7$ to $5 \cdot 2)$ & $9 \cdot 5(7 \cdot 7$ to $11 \cdot 3)$ \\
\hline \multicolumn{7}{|l|}{ Employment status . } \\
\hline No paid employment & $37 \cdot 9 \ddagger(35 \cdot 1$ to $40 \cdot 7)$ & $1 \cdot 7(1 \cdot 2$ to $2 \cdot 2)$ & $3 \cdot 1(1 \cdot 1$ to $5 \cdot 0)$ & $0.708(0.500$ to 0.917$)$ & $3.8(2.9$ to 4.8$)$ & $7 \cdot 5(5 \cdot 2$ to $9 \cdot 8)$ \\
\hline Paid employment & $33.9(31.8$ to 36.0$)$ & $1.4(1.0$ to 1.8$)$ & $6.0(2.7$ to 9.4$)$ & $0.729(0.556$ to 0.903$)$ & $4.6(3.7$ to 5.6$)$ & $10 \cdot 1(7 \cdot 6$ to $12 \cdot 6)$ \\
\hline
\end{tabular}

Mean values with $95 \%$ CI. Significant differences $(p<0.05)$ compared with: * low; $\nmid$ high; $\$ married; $\ddagger$ paid.

Table 4 Variables of disease severity measured at last visit to the outpatient clinic according to level of education, marital status and employment status in 127 female patients with rheumatoid arthritis

\begin{tabular}{|c|c|c|c|c|}
\hline & \multirow[t]{2}{*}{ Erosion score } & \multirow[t]{2}{*}{$H A Q$ score } & \multicolumn{2}{|c|}{ Progressive disease (\%) according to } \\
\hline & & & Physician & Patient \\
\hline \multicolumn{5}{|l|}{ Education level } \\
\hline Low & $38 \cdot 0(29 \cdot 2$ to $46 \cdot 8)$ & $0.793(0.609$ to 0.977$)$ & $54 \cdot 5(43 \cdot 4$ to $65 \cdot 7)$ & $23.1(13.7$ to 32.4$)$ \\
\hline Medium & $48 \cdot 8(32 \cdot 3$ to $65 \cdot 2)$ & $0.963^{\star}(0.705$ to 1.221$)$ & $53 \cdot 3(35.5$ to $71 \cdot 2)$ & $33.3(16.7$ to 50.2$)$ \\
\hline High & $28.5(11 \cdot 1$ to $45 \cdot 9)$ & $0.486(0.219$ to 0.752$)$ & $44.4(21.4$ to 67.4$)$ & $11 \cdot 1(1.4$ to $34 \cdot 7)$ \\
\hline \multicolumn{5}{|l|}{ Marital status } \\
\hline Unmarried & $28 \cdot 8(13.1$ to $44 \cdot 5)$ & $0.848(0.515$ to 1.181$)$ & $37 \cdot 5(18 \cdot 1$ to $56 \cdot 9)$ & $20 \cdot 0(4 \cdot 3$ to $35 \cdot 7)$ \\
\hline Married & $41 \cdot 5(33 \cdot 6$ to $49 \cdot 3)$ & $0.776(0.628$ to 0.924$)$ & $56 \cdot 9(47 \cdot 3$ to $66 \cdot 5)$ & $24 \cdot 5(16 \cdot 2$ to $32 \cdot 9)$ \\
\hline \multicolumn{5}{|l|}{ Employment status } \\
\hline No paid employment & $33 \cdot 3(21 \cdot 3$ to $45 \cdot 3)$ & $0.627(0.429$ to 0.825$)$ & $48.7(33.0$ to 64.4$)$ & $17 \cdot 5(5 \cdot 7$ to $29 \cdot 3)$ \\
\hline Paid employment & $44 \cdot 2(33.7$ to $54 \cdot 6)$ & $0.892(0.693$ to 1.091$)$ & $56 \cdot 3(44 \cdot 1$ to $68 \cdot 4)$ & $26 \cdot 6(15 \cdot 7$ to $37 \cdot 4)$ \\
\hline
\end{tabular}

Mean values with $95 \%$ CI. ${ }^{\star}$ Significant difference $(p<0.05)$ compared with high.

level, marital status and employment status.

The mean age of patients in the lower education level group was greater than that of patients in the other two educational groups $(p<0.05)$. The mean duration of symptoms was the same in all groups, but patients in the lower and medium education groups had a higher mean HAQ score, erosion score, Ritchie Articular Index, and number of swollen joints at the first visit.

In table 4 , the outcome as measured by the mean values for HAQ score and erosion score at the last visit and the percentages of progressive disease outcome according to patient's and physician's global assessment are shown for each level of formal education, marital status and employment status. Patients in the low and medium level groups had a worse mean HAQ score and erosion score and a greater percentage of patient's and physician's opinion of progressive outcome than patients in the high level group. Unmarried patients had a slightly higher mean HAQ score than married patients, but for other outcome measures the results were the reverse. For all outcome measures patients with paid employment did worse. None of the differences between groups reached statistical significance.

Table 5 presents the crude and adjusted odds ratios for sociodemographic factors and the different outcome variables of RA, measured at the last visit. According to the crude odds ratios, patients with a low or medium education level had a greater risk of a bad outcome irrespective of the definition of outcome. After correction for confounding variables including the initial disease presentation, the greater risk of a poor final HAQ score and erosion score for patients in the low and medium education groups became smaller. The greater risk of a progressive disease outcome as assessed by patient and physician for patients with low and medium education did not remain. Overall, married versus unmarried patients and employed versus unemployed women had a worse outcome. In general, none of the results was statistically significant, all but one of the $95 \%$ confidence intervals including unity.

Table 5 Crude and adjusted ${ }^{*}$ odds ratios (OR) with the $95 \%$ confidence interval of sociodemographic variables for outcome of rheumatoid arthritis measured at last visit in 127 female patients

\begin{tabular}{|c|c|c|c|c|c|c|c|c|}
\hline & \multicolumn{2}{|l|}{ Erosion score } & \multicolumn{2}{|l|}{$H A Q$ score } & \multicolumn{2}{|c|}{ Progressive disease, physician } & \multicolumn{2}{|c|}{ Progressive disease, patient } \\
\hline & Crude OR & Adj $O R$ & Crude OR & $\operatorname{Adj} O R$ & Crude OR & $\operatorname{Adj} \mathrm{OR}$ & Crude OR & $\operatorname{Adj} O R$ \\
\hline Education level & & & & & & & & \\
\hline Medium & $\begin{array}{l}2 \cdot 14 \\
(0 \cdot 67 \text { to } 6 \cdot 79) \\
3 \cdot 40 \\
(0 \cdot 93 \text { to } 12 \cdot 49) \\
1\end{array}$ & $\begin{array}{l}1 \cdot 51 \\
(0 \cdot 37 \text { to } 6 \cdot 15) \\
1 \cdot 94 \\
(0 \cdot 43 \text { to } 8 \cdot 75) \\
1\end{array}$ & $\begin{array}{l}2 \cdot 03 \\
(0 \cdot 42 \text { to } 9 \cdot 89) \\
3 \cdot 68 \\
(0 \cdot 69 \text { to } 19 \cdot 49) \\
1\end{array}$ & $\begin{array}{l}0.83 \\
(0 \cdot 08 \text { to } 8 \cdot 63) \\
1 \cdot 47 \\
(0 \cdot 13 \text { to } 16 \cdot 78) \\
1\end{array}$ & $\begin{array}{l}1 \cdot 50 \\
(0 \cdot 53 \text { to } 4 \cdot 21) \\
1 \cdot 43 \\
(0 \cdot 44 \text { to } 4 \cdot 62) \\
1\end{array}$ & $\begin{array}{l}0 \cdot 48 \\
(0 \cdot 11 \text { to } 2 \cdot 18) \\
0 \cdot 54 \\
(0 \cdot 11 \text { to } 2 \cdot 61) \\
1\end{array}$ & $\begin{array}{l}2 \cdot 72 \\
(0 \cdot 57 \text { to } 12 \cdot 98) \\
4 \cdot 44 \\
(0 \cdot 84 \text { to } 23 \cdot 40) \\
1\end{array}$ & $\begin{array}{l}0 \cdot 91 \\
(0 \cdot 13 \text { to } 6 \cdot 42) \\
1 \cdot 36 \\
(0 \cdot 18 \text { to } 10 \cdot 06) \\
1\end{array}$ \\
\hline Marital status & & & & & & & & \\
\hline $\begin{array}{l}\text { Unmarried } \\
\text { Married }\end{array}$ & $\begin{array}{l}0 \cdot 58 \\
(0 \cdot 22 \text { to } 1 \cdot 52) \\
1\end{array}$ & $\begin{array}{l}1 \cdot 32 \\
(0 \cdot 38 \text { to } 4 \cdot 59) \\
1\end{array}$ & $\begin{array}{l}1.64 \\
(0.59 \text { to } 4.56) \\
1\end{array}$ & $\begin{array}{l}0 \cdot 58 \\
(0 \cdot 08 \text { to } 4 \cdot 27) \\
1\end{array}$ & $\begin{array}{l}0 \cdot 46 \\
(0 \cdot 18 \text { to } 1 \cdot 14) \\
1\end{array}$ & $\begin{array}{l}0 \cdot 35 \\
(0 \cdot 09 \text { to } 1 \cdot 34) \\
1\end{array}$ & $\begin{array}{l}0 \cdot 78 \\
(0 \cdot 26 \text { to } 2 \cdot 32) \\
1\end{array}$ & $\begin{array}{l}0 \cdot 24 \\
(0 \cdot 03 \text { to } 1 \cdot 65) \\
1\end{array}$ \\
\hline $\begin{array}{l}\text { Employment status } \\
\text { No paid employment } \\
\text { Paid employment }\end{array}$ & $\begin{array}{l}0 \cdot 55 \\
(0 \cdot 24 \text { to } 1 \cdot 28) \\
1\end{array}$ & $\begin{array}{l}0.56 \\
(0 \cdot 19 \text { to } 1 \cdot 62) \\
1\end{array}$ & $\begin{array}{l}0.33 \\
(0.11 \text { to } 0.98) \\
1\end{array}$ & $\begin{array}{l}0.09 \\
(0.01 \text { to } 0.68) \\
1\end{array}$ & $\begin{array}{l}0 \cdot 74 \\
(0 \cdot 33 \text { to } 1 \cdot 64) \\
1\end{array}$ & $\begin{array}{l}0 \cdot 72 \\
(0 \cdot 25 \text { to } 2 \cdot 04) \\
1\end{array}$ & $\begin{array}{l}0 \cdot 56 \\
(0 \cdot 21 \text { to } 1 \cdot 51) \\
1\end{array}$ & $\begin{array}{l}0 \cdot 27 \\
(0 \cdot 06 \text { to } 1 \cdot 25) \\
1\end{array}$ \\
\hline
\end{tabular}

^OR adjusted for age, duration of symptoms, use of oral contraceptives and variables representing disease severity at onset. 


\section{Discussion}

The results of the present study showed a trend towards a more severe initial disease presentation for patients in the low and medium education groups compared with the high education group. Patients in the low and medium education groups also had a more severe disease outcome, irrespective of the definition of outcome. However, after correction for confounding variables including the initial disease presentation, the risk for a worse HAQ score and erosion score and the risk for a progressive disease outcome became smaller or disappeared.

Direct comparison of these results with data from other studies is difficult, because of methodological differences. Most studies have been performed on data of patients with a disease duration of more than 10 years before study entry. Although in some studies the results were corrected for disease duration and patient age, differences in outcome in patients with different levels of education might have been related to a poorer initial clinical presentation at study entry. In the present study patients with all three levels of education had the same duration of symptoms at the first visit, but patients in the low and medium education groups had higher mean HAQ scores and erosion scores compared with the high education group. Differences between patients may therefore already have developed or been present in very early stages of the disease. Another possible explanation is that patients in the lower education groups consult a rheumatologist only when they have severe disease, whereas in the high education level group patients with both severe and mild symptoms consult or are referred to a rheumatologist. It is known that in the Netherlands persons with a higher socioeconomic status report more visits to consultants than persons with a lower socioeconomic status. ${ }^{21}$ In the present study, however, there were more women in both the high and the low education level groups compared with the reference population. It remains unexplained why, in the present study, both crude and adjusted results showed that patients in the medium education group had a worse initial presentation and worse outcome than patients in the low education group.

For both other sociodemographic factors, marital status and employment status, the results of the present study were more inconsistent. Unmarried patients had poorer HAQ scores, which is consistent with a recent study on progression of disability in patients with RA. ${ }^{10}$ Other outcome measures were better in the unmarried than in the married patients. All outcome measures were worse in patients who had paid employment at the onset of disease in comparison with patients who had no paid employment. However, as the present study was performed in women, of whom only
$50 \%$ had paid employment, interpretation of these results is difficult.

In conclusion, patients with low and medium levels of education had higher initial erosion and HAQ scores compared with patients with high levels of education, while duration of symptoms was the same in all three groups. There was a trend towards poorer outcome of RA in women with low and medium levels of education, but differences became smaller after adjustment for initial disease presentation. The results for other sociodemographic variables were equivocal. Further research in larger RA populations, including men, should be directed at explaining the differences in the initial disease presentation between patients with different levels of education.

1 Pincus T, Callahan L F. Formal education level as a marker for increased mortality and morbidity in rheumatoid arthritis. F Chron Dis 1985; 38: 973-84.

2 Verbrugge L M, Gates D M, Ike R W. Risk factors for disability among U.S. adults with arthritis. $f$ Clin Epidemiol 1991; 44: 167-82.

3 Callahan L F, Pincus T. Formal education level as a significant marker of clinical status in rheumatoid

arthis. Arthritis Rheum 1988; 31: 1346-57.

Meenan R F, Kazis L E, Anderson J J. The stability of health status in rheumatoid arthritis: a five-year study of patients with established disease. Am F Public Health 1988; 78:

5 Lorish C D, Abraham N, Austin J, Bradley L A, Alarcon G S. Disease and psychosocial factors related to physical functioning in rheumatoid arthritis. F Rheumatol 1991; 18: 1150-7.

6 Wolfe F, Cathey M A. The assessment and prediction of functional disability in rheumatoid arthritis. $\mathcal{F}$ Rheumatol 1991; 18: 1298-306.

7 Leigh J P, Fries J F. Education level and rheumatoid arthritis: evidence from five data centers. $\mathcal{f}$ Rheumatol 1991; 18: 24-34.

8 Leigh J P, Fries J F. Mortality predictors among 263 patients with rheumatoid arthritis. $\mathcal{F}$ Rheumatol 1991; 18: 1307-12.

9 Leigh J P, Fries J F. Predictors of disability in a longitudinal sample of patients with rheumatoid arthritis. Ann Rheum Dis 1992; 51: 581-7.

10 Ward M M, Leigh J P. Marital status and the progression of functional disability in patients with rheumatoid arthritis. Arthritis Rheum 1993; 36: 581-8.

11 Yelin E, Meenan R, Nevitt M, Epstein W. Work disability in rheumatoid arthritis: effects of disease, social and work factors. Ann Int Med 1980; 93: 551-6.

12 Makisara G L, Makisara P. Prognosis of functional capacity and work capacity in rheumatoid arthritis. Clin Rheumatol 1982; 1: 117-25

13 Yelin E, Henke C, Epstein W. The work dynamics of the person with rheumatoid arthritis. Arthritis Rheum 1987; 30: $507-12$.

14 Hazes J M W, Dijkmans B A C, Vandenbroucke J P, de Vries R R P, Cats A. Reduction of the risk of rheumatoid arthritis among women who take oral contraceptives. Arthritis Rheum 1990; 33: 173-80.

15 Ropes M W, Bennett C A, Cobb S, Jacox R, Jessar R. A revision of diagnostic criteria for rheumatoid arthritis. Bull Rheum Dis 1958; 9: 175-6.

16 Arnett F C, Edworthy S M, Bloch D A, et al. The American Rheumatism Association 1987 revised criteria for the classification of rheumatoid arthritis. Arthritis Rheum 1988; 31: 315-24.

17 Siegert C E H, Vleming L J, Vandenbroucke J P, Cats A. Measurement of disability in Dutch rheumatoid arthritis patients. Clin Rheumatol 1984; 3: 305-9.

18 The epidemiology of chronic rheumatism. In: Kellgren J H, ed. Atlas of standard radiographs of arthritis. Vol. 2 . Oxford: ed. Atlas of standard radiographs of arthri

19 Van Zeben D, Hazes J M W, Breedveld F C, Zwinderman A H, Vandenbroucke J P. Which clinical variables contribute to the physician's assessment of medium term outcome in rheumatoid arthritis. $f$ Rheumatol 1993; 20:
33-9.

20 Centraal Bureau voor de Statistiek (Central Bureau of Statistics), Arbeidskrachtentelling 19: 34,42 and Maandstatistiek, February 1983.

21 Mackenbach J P. Socio-economic health differences in the Netherlands: a review of recent empirical findings. Soc Sci Med 1992; 34: 213-26. 